\title{
Maxillary Distomolar Associated with Dentigerous Cyst: An Unusual Entity
}

\author{
Edouard Di Donna *, Loïc Mahé Keller, Annika Neri, Alexandre Perez ${ }^{(D)}$ and Tommaso Lombardi
}

Citation: Di Donna, E.; Keller, L.M.; Neri, A.; Perez, A.; Lombardi, T.

Maxillary Distomolar Associated with Dentigerous Cyst: An Unusual Entity. Oral 2022, 2, 1-6. https:// doi.org/10.3390/oral2010001

Academic Editor: Luca Testarelli

Received: 4 December 2021

Accepted: 31 December 2021

Published: 5 January 2022

Publisher's Note: MDPI stays neutral with regard to jurisdictional claims in published maps and institutional affiliations.

Copyright: () 2022 by the authors Licensee MDPI, Basel, Switzerland. This article is an open access article distributed under the terms and conditions of the Creative Commons Attribution (CC BY) license (https:// creativecommons.org/licenses/by/ $4.0 /)$.

\begin{abstract}
Unit of Oral Surgery and Implantology, Division of Oral Maxillofacial Surgery, Department of Surgery, University Hospitals of Geneva, 1211 Geneva, Switzerland; loic-mahe.keller@hcuge.ch (L.M.K.); annika.neri@hcuge.ch (A.N.); alexandre.perez@hcuge.ch (A.P.); tommaso.lombardi@hcuge.ch (T.L.) * Correspondence: Edouard.didonna@hcuge.ch; Tel.: +41-79-701-19-97
\end{abstract}

\begin{abstract}
Supernumerary teeth may be encountered as an incidental finding on a radiograph. When impacted, they may be associated with clinical signs related to different problems such as failure of eruption, teeth displacement, root resorption or cystic lesions. They may occur in primary and permanent dentition, in both the maxilla and mandible and can be single or multiple in patients with syndromes. Mesiodens is the most commonly impacted tooth and appears between the central maxillary incisors in pediatric ages. Supernumerary teeth distal to the third molar are rare, usually impacted and referred to as a distomolar. A 46-year-old male consulted with the main complaint of pain on the left side of the maxilla. A panoramic radiograph revealed a right impacted maxillary fourth molar located posterior to the third molar associated with a pericoronal radiolucency. The supernumerary tooth was removed surgically under local anesthesia and the pericoronal lesion enucleated. Histopathological examination was consistent with the diagnosis of a dentigerous cyst associated with an impacted distomolar. Healing was uneventful, and the patients remained asymptomatic. The occurrence of an impacted maxillary distomolar is rare and even rarer the association with a dentigerous cyst.
\end{abstract}

Keywords: supernumerary teeth; distomolar; fourth molar; dentigerous cyst; jaws; oral pathology

\section{Introduction}

A supernumerary tooth, also called hyperdontia, is a medical condition defined by an excess number of teeth, which can be normal or with coronary or radicular malformations [1]. According to their locations, supernumerary teeth are categorized differently: mesiodens if located in the middle suture of the upper maxilla, paramalor if situated buccally or palatally to one of the molars and distomolar, also known as the fourth molar, if located behind the third molar. The latter can have a normal morphology or be dysmorphic in shape. Distomolar teeth may partially or completely erupt, but in $92.7 \%$ of cases, they are impacted [2]. They are considered rare, according to the literature, and the prevalence presents geographic variations: Kurt et al. [2] reported a prevalence of $0.32 \%$ in Turkish populations; Thomas et al. found [3] a prevalence of 2.1\% in Indian populations among 1000 panoramic radiograph; in Greek populations, Mitsea et al. [4] found distomolars' frequency ranged from $0.84 \%$ to $0.95 \%$ in the maxilla and from 0.11 to $0.22 \%$ in the mandible. Like any impacted tooth, complications, such as dental displacement, root resorption, infections, cysts or tumors, can be observed [5]. The development of a dentigerous cyst associated with an impacted supernumerary tooth is rare, but when it appears, in $90 \%$ of cases, it is associated with a mesiodens [6].

The identification of supernumerary teeth is usually carried out using a panoramic radiograph. Usually, the removal of the supernumerary tooth is the treatment of choice.

The aim of this article is to present a rare case of a maxillary supernumerary distomolar associated with a dentigerous cyst. 


\section{Case Presentation}

A 46-year-old Indian male, known for psychotic disorders and chronic alcoholism, was referred to our unit for severe pain (8/10 on the visual scale), which was present for three days and located in the upper left side of the jaw. The extraoral clinical examination was unremarkable. An intraoral examination revealed painful palpation of the left tuberosity region, and mucosal appearance was normal. The dental examination revealed the presence of a restorative treatment of tooth \#28, responding positively to the sensitivity test and with periodontal pockets of $7 \mathrm{~mm}$.

The panoramic radiograph (Figure 1) and cranial CT scan (Figures 2 and 3) showed a well-defined unilocular radiolucency, associated with the crown of an unerupted supernumerary tooth \#28 (distomolar). The tooth appears dysmorphic and in a horizontal position. The lesion is about $13 \mathrm{~mm}$ in diameter and projected onto the maxillary sinus floor. The treatment plan was a surgical extraction and lesion enucleation under local anesthesia. A full-thickness mucoperiosteal flap on the labial side was reflected, an adequate amount of bone was removed using the rotary cutting instruments, and the fourth impacted supernumerary tooth was extracted and the entire lesion enucleated. The labial flap was repositioned and sutured. Macroscopic examination of the tooth showed a dysmorphic crown and an irregular grayish soft fragment, measuring $1.3 \mathrm{~cm} \times 0.4-1.0 \mathrm{~cm} \times 0.1-0.4 \mathrm{~cm}$. Microscopic analysis of the pericoronal tissue revealed a fibrovascular connective tissue lined in places by a non-keratinized squamous epithelium of irregular thickness, showing a flat interface with the fibrous connective wall (Figure 4). The latter contained a few lymphocytes and some small dystrophic calcifications. The histological aspect was consistent with the diagnosis of dentigerous cyst related to an impacted distomolar tooth. Healing was uneventful, and the patient remained asymptomatic. At two weeks, clinical healing was satisfactory, and subsequently, the patient was lost for follow-up.

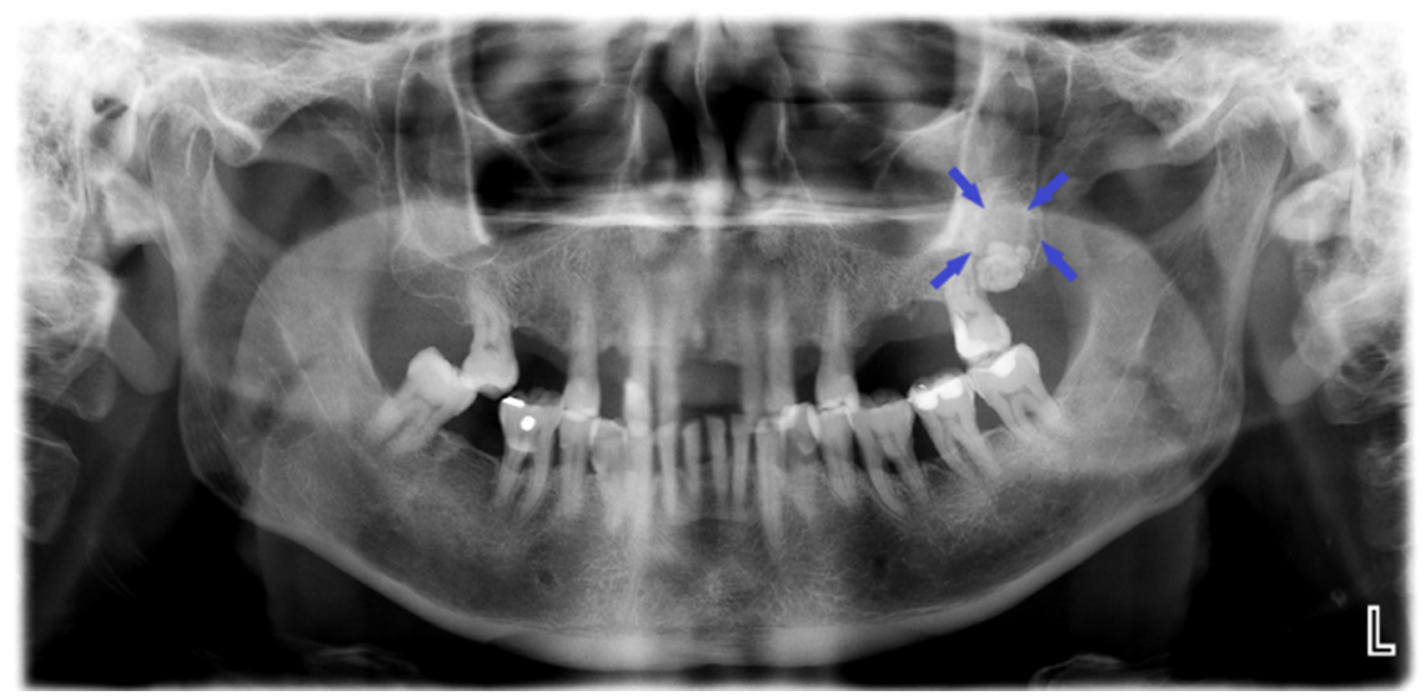

Figure 1. Panoramic radiograph. 


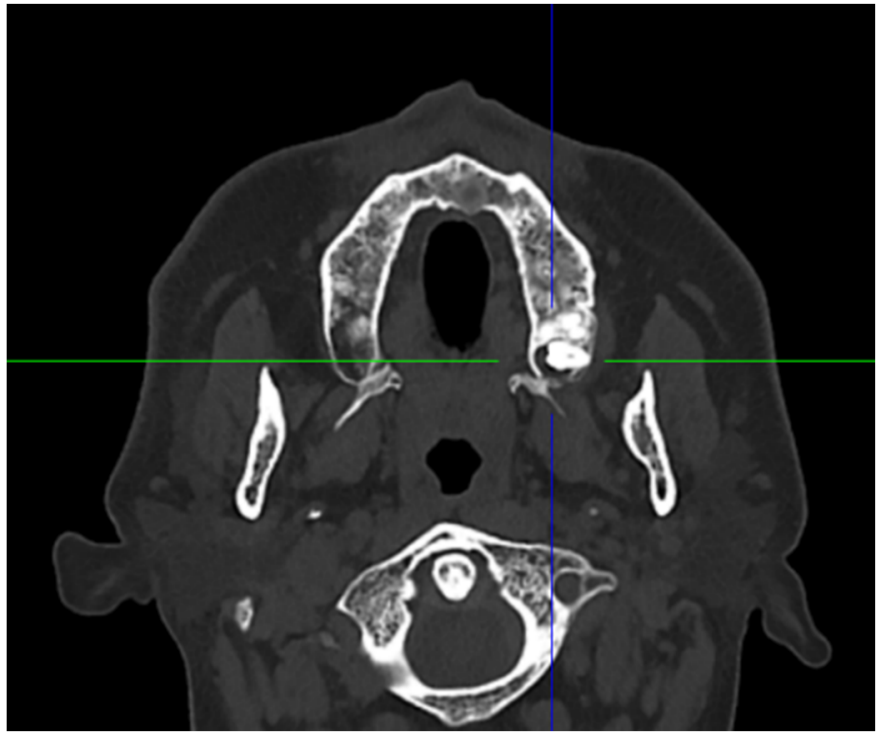

Figure 2. Axial CT Scan.

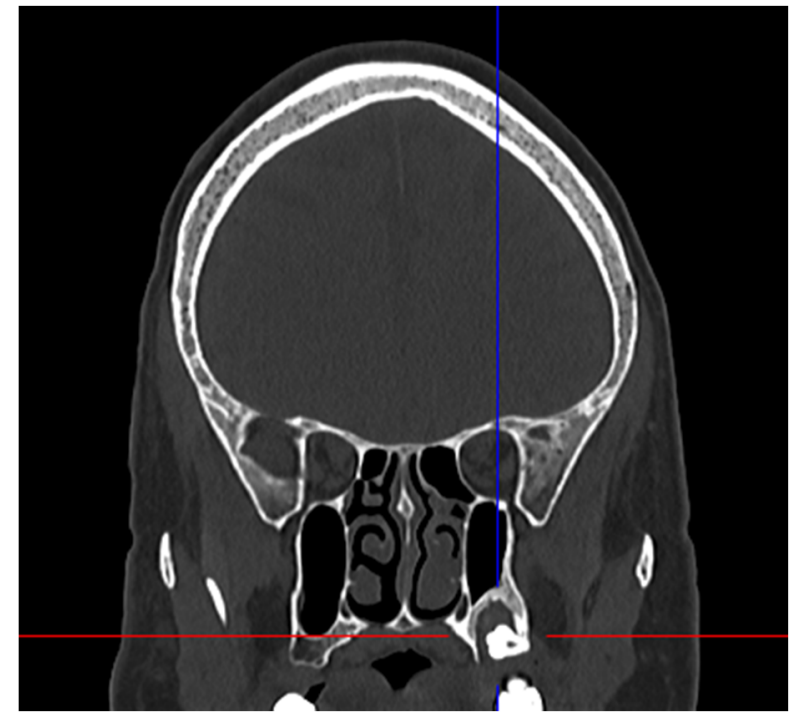

Figure 3. Coronal CT Scan.

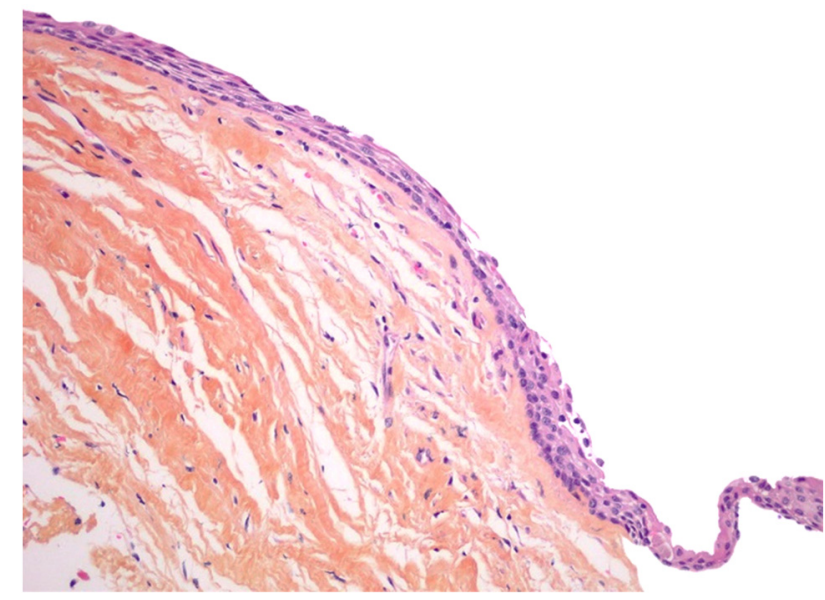

Figure 4. Histopathological aspect of the cyst. 


\section{Discussion}

Hyperdontia is a medical condition characterized by an excess of teeth. Pippi et al. [7], analyzing the prevalence of supernumerary teeth in previous studies, found rates going from $0.04 \%$ to $2.29 \%$. Another study found that males were affected twice as much as females [8].

Most supernumerary teeth are idiopathic, but they also occur in genetic syndromes, the most common being cleidocranial dysplasia, Gardner's syndrome, Ehlers-Danlos syndrome, and Fabry-Anderson syndrome $[9,10]$.

The etiology of supernumerary teeth has not been clearly elucidated. Several theories on the etiology have been proposed in the literature. Although genetics and environmental factors have been evoked, the most accepted theory is the hyperactivity of the dental lamina, leading to the development of supernumerary teeth [11]. Supernumerary teeth can appear as single or multiple and can be unilateral or bilateral [8]. According to their morphology, they are classified into four categories: conical, tuberculate, supplemental, and odontomatous [12]. Supernumerary teeth are located in the upper jaw in $90 \%$ of cases. When they are located between the two upper central incisors, they are referred to as mesiodens. Their prevalence is $46-60 \%$, and they are then followed, in order of frequency, by the upper molars, upper lateral incisors, mandibular premolars, and mandibular molars [11]. Distomolars are supernumerary teeth that are located distal to the molars. Their prevalence varies between populations and ranges from $0.1 \%$ to $2.1 \%$, and in $92.7 \%$ of cases, they are impacted [2-4]. The pathologies frequently associated with supernumerary teeth are: retention of adjacent teeth, dental malposition, or diastema. The development of a dentigerous cyst associated with an impacted supernumerary tooth is rare, and in $90 \%$ of cases, is associated with a mesiodens [5,6]. According to the 2017 World Health Organization classification, the dentigerous cyst is the most frequent odontogenic cyst, with a prevalence of $20.6 \%$. It affects all ages, with a peak incidence between 20 and 40 years of age. Men are more affected [13]. Dentigerous cysts are associated with mandibular third molars in $75 \%$ of cases, followed by maxillary canines, maxillary third molars, and mandibular second premolars [14]. These cystic lesions, often asymptomatic, are incidentally discovered on radiological exams, or, when infected, symptoms, such as pain and swelling, may appear [15]. On radiological exam, the cyst presents as a well-defined, unilocular radiolucent lesion, surrounding the crown of an impacted tooth, which may be displaced. Occasionally, resorptions of adjacent teeth may be seen. True neoplasms are known to develop in the cystic lining of dentigerous cysts, such as ameloblastomas and adenomatoid odontogenic tumors. [16]. Nimonkar et al. [17] reported three cases of ameloblastomas arising from dentigerous cysts in three different patients treated by wide enucleation and chemical cauterization.

Macroscopically, the cyst is attached to the cementoenamel junction of the tooth. The histological analysis of an uninflamed dentigerous cyst shows a thin non-keratinized squamous epithelium, with a fibrous wall devoid of inflammatory infiltrate. Occasionally, the remnants cells of Serres are present and may calcify and appear as small calcifications [14]. Dentigerous cysts are usually treated by enucleation and concomitant tooth removal [18].

After reviewing the literature, to the best of our knowledge, only two cases of dentigerous cysts associated with distomolars were reported (Table 1), stressing the rarity of such a lesion. These were all associated with mandibular distomolars. The patients were two adult women; in one case, the cyst was asymptomatic, and in the other, it was painful and associated with swelling. Our patient was a man and presented with severe pain.

Supernumerary molars on the dental arch are not usually associated with complications in the oral cavity. However, when they are impacted, they can cause a whole series of pathological conditions, such as infections, carious or periodontal lesions, and cystic development [12]. The treatment of distodens depends on the severity, and therapeutic options are mainly surgical removal or clinical and radiological follow-up [11]. If the supernumerary tooth is impacted and associated with one of the complications cited above, extraction is the treatment of choice. 
Table 1. Supernumerary distomolar associated with a dentigerous cyst (cases described in the literature).

\begin{tabular}{cccccc}
\hline Authors & Gender & Patient Age (Years) & Symptoms & Site & Treatment \\
\hline Morales ND 2018 [19] & F & 34 & Swelling, Pain & Mandibular Distomolar & Enucleation \\
Hara et al. 2019 [20] & F & 43 & Asymptomatic & Mandibular Distomolar & Enucleation \\
Filho et al. 2020 [21] & M & 30 & Pain & Mandibular Distomolar & Enucleation \\
Present Case & M & 46 & Pain & Maxillary distomolar & Enucleation \\
\hline
\end{tabular}

\section{Conclusions}

Supernumerary distomolars are rare, usually asymptomatic and discovered on radiographs. In this article, we wanted to stress the importance of early diagnosis of these impacted teeth since it may prevent the development of cystic lesions as in our patient. The dentigerous cyst is considered to be a docile lesion but possesses a potential for neoplastic transformation. Some authors recommend radiological follow-up of distomolar impacted teeth. Due to the pathologies associated with impacted teeth that have been previously discussed, the extraction of these teeth is recommended since it may prevent major complications and minimize the treatment.

Author Contributions: Conceptualization, T.L. and A.P.; methodology, E.D.D., A.N. and L.M.K.; validation, T.L. and A.P.; resources, E.D.D.; writing-original draft preparation, E.D.D.; writingreview and editing, T.L. All authors have read and agreed to the published version of the manuscript.

Funding: This research received no external funding.

Institutional Review Board Statement: Ethical review and approval were waived for this study, and the study is based on common clinical practices.

Informed Consent Statement: Written informed consent has been obtained from the patient to publish this paper.

Data Availability Statement: Data are contained within the article.

Acknowledgments: The authors are grateful to Vincent Lenoir for the radiology examination.

Conflicts of Interest: The authors declare no conflict of interest.

\section{References}

1. Arandi, N. Distomolars: An overview and 3 case reports. Dent. Oral Craniofac. Res. 2017, 4, 1-3. [CrossRef]

2. Kurt, H.; Suer, T.B.; Senel, B.; Avsever, H. A retrospective observational study of the frequency of distomolar teeth in a population. Cumhur. Dent. J. 2015, 18, 335-342.

3. Thomas, S.A.; Sherubin, E.; Pillai, K.S. A study on the Prevalence and Characteristics of Distomolar among 1000 Panoramix Ragiographs. J. Indian Acad. Oral Med. Radiol. 2013, 3, 169-172.

4. Mitsea, A.; Vardas, E.; Papachatzopoulou, A.; Kalfountzos, G.; Leventis, M.; Tsiklakis, K. The frequency of non-syndromic distomolar teeth in a Greek population sample? J. Clin. Exp. Dent. 2015, 5, 589-594. [CrossRef] [PubMed]

5. Russell, K.A.; Folwarczna, M.A. Mesiodens diagnosis and management of a common supernumerary tooth. J. Can. Dent. Assoc. 2003, 6, 362-366.

6. Lustmann, J.; Bodner, L. Dentigerous cysts associated with supernumerary teeth. Int. J. Oral Maxillofac. Surg. 1988, 2, 100-102. [CrossRef]

7. Pippi, R. Odontomas and supernumerary teeth: Is there a common origin? Int. J. Med. Sci. 2014, 12, 1282-1297. [CrossRef] [PubMed]

8. Parolia, A.; Kundabala, M.; Dahal, M.; Mohan, M.; Thomas, M.S. Management of supernumerary teeth. J. Conserv. Dent. 2011, 3, 221-224. [CrossRef] [PubMed]

9. Demiriz, L.; Durmuşlar, M.C.; Mısır, A.F. Prevalence and characteristics of supernumerary teeth: A survey on 7348 people. J. Int. Soc. Prev. Community Dent. 2015, 1, 39-43.

10. Lubinsky, M.; Kantaputra, P.N. Syndromes with supernumerary teeth. Am. J. Med. Genet. A 2016, 10, 2611-2616. [CrossRef] [PubMed]

11. Rajab, L.D.; Hamdan, M.A. Supernumerary teeth: Review of the literature and a survey of 152 cases. Int. J. Paediatr. Dent. 2002, 4, 244-254. [CrossRef] [PubMed] 
12. Mallineni, S.K. Supernumerary teeth: Review of the literature with recent updates. In Conference Paper in Science; Hindawi: London, UK, 2014; pp. 1-6.

13. Johnson, N.R.; Gannon, O.M.; Savage, N.W.; Batstone, M.D. Frequency of odontogenic cysts and tumours: A systematic review. J. Investig. Clin. Dent. 2014, 1, 9-14. [CrossRef] [PubMed]

14. Jones, A.V.; Craig, G.T.; Franklin, C.D. Range and demographics of odontogenic cysts diagnosed in a UK population over a 30-year period. J. Oral Pathol. Med. 2006, 8, 500-507. [CrossRef] [PubMed]

15. Thompson, L.D. Dentigerous cyst. Ear Nose Throat 2018, 3, 57. [CrossRef] [PubMed]

16. Yasouka, T.; Yonemoto, K.; Kato, Y.; Tatematsu, N. Squamous cell carcinoma arisingin dental cyst. J. Oral Maxillofac. Surg. 2000, 58, 900-905. [CrossRef] [PubMed]

17. Nimonkar, P.V.; Nimonkara, S.V.; Mandlekara, G.P.; Borleb, R.M.; Gadbailba, A.R. Ameloblastoma arising in a dentigerous cyst: Report of three cases. J. Oral Maxillofac. Surg. Med. Pathol. 2012, 2, 233-237. [CrossRef]

18. Wright, J.M.; Vered, M. Update from the 4th Edition of the World Health Organization Classification of Head and Neck Tumours: Odontogenic and Maxillofacial Bone Tumors. Head Neck Pathol. 2017, 1, 68-77. [CrossRef] [PubMed]

19. Navarro, D.M.; Capote, J.A.M. Distomolar Supernumerary in the mandibular ramus associated with a dentigerous cyst. A case presentation. Rev. Habanera Cienc. Medicas 2018, 17, 255-264.

20. Hara, K.; Tsuchiya, S.; Hagiwara, S.; Fujio, M.; Sayo, A.; Hideharu, H. A dentigerous cyst associated with a supernumerary tooth (fourth molar) in the mandibular ramus: A case report. J. Oral Maxillofac. Surg. Med. Pathol. 2019, 2, 98-102. [CrossRef]

21. Filho, M.J.S.F.; de Andrade, R.; Prestes, T.P.; Cavalcante, F.A.; do Nascimento, J.R.; Aguiar, J.L.; Milério, L.R.; Barro, D.N.R. A dentigerous cyst associated with a supernumerary fourth molar in the mandibular ramus: A case report. Braz. J. Dev. 2020, 6, 93220-93229. [CrossRef] 